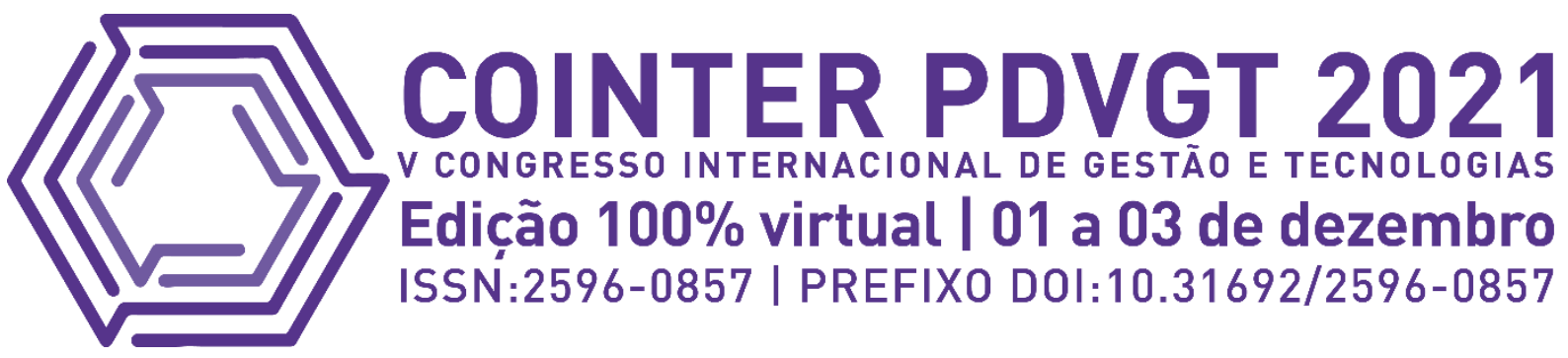

\title{
PERSPECTIVAS DOS COORDENADORES DE EXTENSÃO ACERCA DO TEMA EMPREENDEDORISMO NO IFPE.
}

\section{PERSPECTIVAS DE LOS COORDINADORES DE EXTENSIÓN DEL TEMA DE EMPRENDIMIENTO EN IFPE.}

\section{PERSPECTIVES OF THE ENTREPRENEURSHIP EXTENSION COORDINATORS AT IFPE.}

Apresentação: Comunicação Oral

\begin{abstract}
LINS, Felipe Martins Macedo ${ }^{1}$; VASCONCELOS, Marcelo Alexandre de ${ }^{2}$; SILVA, Erick Viana da ${ }^{3}$
\end{abstract}
DOI: https://doi.org/10.31692/2596-0857.VCOINTERPDVGT.0036

\section{RESUMO}

É importante enunciar que o conceito de empreendedorismo, vem sendo cada vez mais reconhecido em vários países, devido a necessidade de conhecimento do tema, junto com a educação empreendedora para a formação de uma nação. Esse tema vem sendo estudado, porém carece de uma maior análise e discussão, relacionando o ensino, a pesquisa e extensão, com o propósito de disseminar e esclarecer de forma mais compreensível. Com base nessas confirmações, essa pesquisa tem como objetivo identificar as perspectivas dos coordenadores de extensão do IFPE que possuam relação com ações empreendedoras, analisando a percepção e então, explicitando mais sobre a temática. Foi proposto aos entrevistados um questionário, capaz de identificar o âmbito profissional e global dos questionados e os resultados da pesquisa mostram a perspectiva sobre o empreendedorismo nos seus respectivos Campus, de 14 dos 16 Coordenadores de Extensão do IFPE (Instituto Federal de Pernambuco) abrangendo ações, programas, projetos, desafios, experiências e conhecimento sobre o tema. Assim, colaborando para a sedimentação da inserção da temática no ambiente acadêmico devido a sua relevância. Pela visão dos coordenadores de Extensão, foi possível analisar que empreender não é apenas uma forma de acervo de estudos, contudo a formação e a construção de uma cultura, princípios, atitudes, entre outros aspectos e é necessário ainda mais conhecimento sobre o tema, alinhado com engajamento e estrutura.

\footnotetext{
${ }^{1}$ Engenharia Mecânica, Instituto Federal de Pernambuco, felipemm197@ gmail.com

${ }^{2}$ CADM/DAFG, Instituto Federal de Pernambuco, marceloalexandre@recife.ifpe.edu.br

${ }^{3}$ CADM/DAFG, Instituto Federal de Pernambuco, erick.viana@recife.ifpe.edu.br
} 


\title{
TEMA EMPREENDEDORISMO NO IFPE
}

Palavras-Chave: Cultura Empreenderora, Educação Empreendedora, Inovação.

\section{RESUMEN}

Es importante señalar que el concepto de emprendimiento ha sido cada vez más reconocido en varios países, debido a la necesidad de conocimiento del tema, junto con la educación emprendedora para la formación de una nación. Este tema ha sido estudiado, pero necesita un mayor análisis y discusión, relacionando docencia, investigación y extensión, con el propósito de difundir y esclarecer de una manera más comprensible. Con base en estas confirmaciones, esta investigación tiene como objetivo identificar las perspectivas de los coordinadores de extensión de IFPE que se relacionan con las acciones emprendedoras, analizando la percepción y luego explicando más sobre el tema. Se propuso a los encuestados un cuestionario con preguntas perspicaces, capaz de identificar el alcance profesional y global de los encuestados y los resultados de la encuesta muestran la perspectiva sobre el emprendimiento en su respectivo Campus, de 14 de los 16 Coordinadores de Extensión del IFPE (Instituto Federal de Pernambuco) abarcando acciones, programas, proyectos, desafíos, experiencias y conocimientos sobre el tema. Contribuyendo así a la sedimentación de la inserción del tema en el ámbito académico por su relevancia. Desde el punto de vista de los coordinadores de Extensión, se pudo analizar que el emprendimiento no es solo una forma de recolección de estudios, sino la formación y construcción de una cultura, principios, actitudes, entre otros aspectos, e incluso más conocimiento sobre el se necesita un tema, alineado con el compromiso y la estructura.

Palabras Clave: Cultura Empreenderora, Educación Empreendedora, Innovación.

\begin{abstract}
It is important to state that the concept of entrepreneurship has been increasingly recognized in several countries, due to the need for knowledge of the subject, together with entrepreneurial education for the formation of a nation. This topic has been studied, but it needs further analysis and discussion, relating teaching, research and extension, with the purpose of disseminating and clarifying in a more understandable way. Based on these confirmations, this research aims to identify the perspectives of the IFPE extension coordinators that are related to entrepreneurial actions, analyzing the perception and then explaining more about the theme. A questionnaire with insightful questions was proposed to respondents, able to identify the professional and global scope of respondents and the survey results show the perspective on entrepreneurship in their respective Campus, from 14 of the 16 Extension Coordinators of the IFPE (Federal Institute of Pernambuco ) covering actions, programs, projects, challenges, experiences and knowledge on the subject. Thus, contributing to the sedimentation of the insertion of the theme in the academic environment due to its relevance. From the point of view of the Extension coordinators, it was possible to analyze that undertaking is not just a form of collection of studies, but the formation and construction of a culture, principles, attitudes, among other aspects, and even more knowledge about the topic is needed, aligned with engagement and structure.
\end{abstract}

Keywords: Culture Entrepreneurial, Entrepreneurial Education, Innovation. 


\section{INTRODUÇÃO}

Hoje é realidade em muitas instituições de ensino, a capacidade de educar e buscar integrar métodos de ensino, pesquisa e extensão. Na perspectiva de pesquisa, o tema empreendedorismo, é aplicado e estudado na forma de identificar as atividades, perspectivas, limitantes e desafios, experiências exitosas que possam formar um repositório de informações capaz de possibilitar estratégias para fomentar o espírito empreendedor. Nesse sentido, cabe a análise dos principais autores do tema, a fins de revisar e contextualizar a educação empreendedora, e o empreendedorismo no cenário atual. Ribeiro (2014) afirma que o empreendedorismo é considerado uma maneira de buscar oportunidades e inovações de forma criativa ou de manutenção de um empreendimento.

Vale destacar que o ensino do empreendedorismo surge, depois de um longo caminho da compreensão conceitual do empreendedorismo, principalmente no cerne central inicial, voltada para geração de negócios. A quebra de uma ruptura daquele que cria algo, e passa essa criação, esta contemplada, em aspectos de inovação. E esse persona é analisado compreendido, mas a grande indagação, esse persona, professor, empreendedor, objeto de estudo que foi compreendido, tem como ensinar isso a outros. O ponto central da discussão do ensino do empreendedorismo, é a própria trajetória conceitual e de estudo que o empreendedorismo passou e que atualmente passa.

A educação empreendedora vem atravessando um longo percurso pelo decorrer do tempo e se semeou em programas como o de formação, em disciplinas e atividades de preparação, contudo as investigações a cerca desse tema necessitam de mais estudos teóricos e empíricos (LIMA et. al., 2014a). Ao passar dos anos, os estudos sobre "empreendedorismo" percorreram muito em termos de importância, todavia o tema da "educação empreendedora" necessita de uma discussão mais embasada e sólida, que ajude no seu esclarecimento, detalhamento e norteamento, e então, que dissemine de forma mais efetiva (LOPEZ, 2010). Existe uma importância de se analisar melhor o que é a educação empreendedora, buscando entendimento em relação a questionamentos como: realmente existe conhecimento sobre o tema educação empreendedora? Como os empreendedores aprendem? Como o empreendedorismo se desenvolve? O empreendedorismo pode ser ensinado/aprendido em instituições de ensino? O que ensinar? Como estimular? Como potencializar e facilitar essas aprendizagens? Partindo dessas analises, infere-se que "as dúvidas ainda permanecem, a despeito de serem frequentemente formuladas, e que se carece de um quadro referencial para guiar nossas decisões e ações nessa área" (LOPES, 2010, p. 19).

Na educação empreendedora, o aluno passa a ser o centro das atenções, onde ele passa a ser visto e valorizado pelas suas particularidades. Oliveira e Barbosa (2014) destacam que o ensino do empreendedorismo requer diferentes abordagens, algumas das quais ainda se desejam que sejam 


\section{TEMA EMPREENDEDORISMO NO IFPE}

aceitas. Contudo, entendem que não basta apenas introduzir práticas ou propostas denominadas "modernas". Para os autores, o importante é adequar as demandas e peculiaridades dos interessados, ou, seja dos próprios estudantes.

A importância das universidades e instituições de ensino de atuarem nesta frente como fomentadoras da educação e atitude empreendedora nos estudantes, promovem o desenvolvimento econômico e social, que são amparadas no princípio constitucional que visa garantir a qualidade do ensino, em seus diversos níveis e modalidades e é regulamentado pela Lei de Diretrizes e Bases da Educação Nacional (Lei 9.394, 1996). No entanto, este ambiente ainda requer condicionantes para que o processo de aprendizagem esteja alinhado com as demandas do mercado e possibilite com urgência uma reflexão acerca do papel de todos os atores em relação as instituições de ensino, comunidade externa e toda sociedade de forma que possam surgir contribuições para estimular e desenvolver a educação empreendedora dentro das universidades.

O IFPE (Instituto Federal de Pernambuco) é uma instituição centenária e, ao mesmo tempo, inovadora. Existem 16 Campi que são distribuídos do litoral ao sertão de Pernambuco, aliado a uma ampla rede de Educação a Distância, com a realidade de 11 polos, a Instituição alia seu viés profissionalizante de origem, que busca a atender às demandas do mercado produtivo e da indústria, ao desenvolvimento do saber científico e à uma formação humanística. No IFPE, as atividades de ensino estão diretamente associadas à pesquisa e à extensão. O envolvimento com trabalhos científicos é incentivado desde as etapas iniciais através de bolsas, programas e eventos acadêmicos. Pode-se relacionar a inovação com o empreendedorismo presente no Instituto, exemplo disso é o "PDV", Programa Despertando Vocações, que busca "desenvolver ações que despertem o interesse da sociedade pelas carreiras profissionais das áreas de atuação do IIDV: Formação de Professores, Ciências Agrárias, Gestão, Tecnologias, Saúde e Artes através de atividades de Ensino, Pesquisa, Extensão no formato de rede de cooperação". Outro exemplo de movimento estudantil ligado ao empreendedorismo, e hoje presente em Campus do IFPE, são as Empresas Juniores, são constituídas por alunos matriculados em cursos de graduação em instituições de ensino superior, formando uma associação civil com o intuito de realizar projetos e serviços que colaborem para o desenvolvimento do país e de formar profissionais capacitados e comprometidos com o que é proposto e mercado de trabalho.

Dessa forma, é importante ressaltar que esse artigo está vinculado ao projeto: Formação empreendedora, protagonismo estudantil e mudanças organizacionais em instituições de ensino brasileiras. Com isso, o objetivo desse trabalho é identificar as perspectivas dos coordenadores de extensão do IFPE que possuam relação com ações empreendedoras, analisando a percepção e então, explicitando mais sobre a temática, fazendo analogias pertinentes e mostrando os pontos de vistas dos coordenadores nos diferentes Campus do IFPE, a fins de colaborar para a sedimentação da inserção da temática no ambiente acadêmico devido a sua relevância. 


\section{Objetivo Geral}

Identificar as perspectivas dos coordenadores de extensão do IFPE que possuam relação com ações empreendedoras, analisando a percepção e então, explicitando mais sobre a temática.

\section{Objetivos Específicos}

- Identificar o perfil dos coordenadores de extensão do IFPE

- Mapear a percepção dos coordenadores acerca da Educação empreendedora

- Identificar as principais dificuldades e avanços percebidos pelos sujeitos participantes.

\section{FUNDAMENTAÇÃO TEÓRICA}

A difusão do espírito empreendedor tem reflexo na criação de empregos, renda, desenvolvimento social e econômico. No contexto brasileiro, é necessário oportunizar e intensificar "uma educação empreendedora que permita que uma maior proporção do seu capital humano desenvolva o seu potencial empreendedor" (DOLABELA; FILION, 2013, p. 154). Os Programas de Educação Empreendedora, disseminados e até hoje, utilizados em alguns aspectos em instituições públicas e privadas a nível global. Tschá e Cruz Neto (2014) analisam que as universidades auxiliam na amplificação da "cultura empreendedora" presenciando a "educação empreendedora", que estimule não apenas alunos, mas também professores "a despertarem dentro de si o espírito empreendedor e a explorarem o espaço potencial para o empreendedorismo, transformando realidades por meio dos empreendimentos que podem desenvolver economicamente e socialmente um país e uma sociedade" (TSCHÁ; CRUZ NETO, 2014, p. 66). Tais programas auxiliam na formação de profissionais que, junto à obtenção de informações e conhecimentos técnicos em seu campo de formação ou área de atuação, abrangem alusões imprescindíveis para a sua formação profissional, fundamentam a perspectiva de um mundo de oportunidades ao seu redor e estimulam a considerar a opção da carreira empreendedora.

Diferentes autores indicam que o ensino de empreendedorismo precisa aderir uma metodologia particular, distinto da empregada no ensino tradicional (LOPES, 2010; DOLABELA; FILION, 2013; LIMA et. al. 2015b). Dolabela e Filion (2013) contemplam uma modificação drástica as maneiras habituais de ensino, que se inclinam a passagem de informação e conhecimento, visando uma instrução a cerca de em pensar de forma com iniciativa e autônoma.

A necessidade e importância da educação empreendedora para a ampliação de um país tem sido identificada, e isso não apenas no Brasil, mas em diversos outros países. Pode-se 


\section{TEMA EMPREENDEDORISMO NO IFPE}

observar que vem sendo proposto como prioritária até mesmo politicamente, economicamente e academicamente, abrangendo discussões até mesmo das Nações Unidas (UNCTAD, 2015; LIMA et. al., 2015a). Conferências promovidas pelo órgão internacional da ONU que pondera a economia e indicam áreas-chave para a educação empreendedora: a) incorporação do empreendedorismo na educação e treinamento, b) o desenvolvimento curricular, c) o desenvolvimento do professor e d) o engajamento com o setor privado (UNCTAD, 2011).

\section{METODOLOGIA}

A pesquisa foi de natureza qualitativa e teve como objetivo identificar as Perspectivas dos coordenadores de extensão acerca do tema empreendedorismo no IFPE que possuam relação com ações empreendedoras, salientando que o Campo de pesquisa utilizado para conseguir os dados foram todos os 16 (dezesseis) Campi do IFPE em Pernambuco e os sujeitos de pesquisa foram os coordenadores de Extensão de cada Campus de Institutos Federais em Pernambuco. Vale salientar uma passagem de forma quantitativa, devido à algumas perguntas do formulário utilizadas para fins estatísticos.

A investigação foi constituída em duas etapas, aplicação do formulário aos coordenadores de Extensão do IFPE, com perguntas relacionadas ao empreendedorismo, educação empreendedora e ação empreendedora análise buscando compreender a visão dos mesmos, relacionada ao desenvolvimento do empreendedorismo no IFPE. Feito isso, a análise da literatura, de artigos, revistas e livros foram de grande importância para que o estudo mais aprofundado sobre o tema, fosse feito.

Como pode ser observado no Apêndice 1, o procedimento utilizado nessa pesquisa, foi a elaboração e aplicação de um formulário online, cabe ressaltar que o mesmo formulário foi enviado via e-mail para todos os departamentos e coordenadores de extensão dos 16 (Dezesseis) Campi do IFPE.

Relacionado a criação do Formulário, foi elaborado na plataforma do Google, o Google Forms, constituindo por 10 (Dez) perguntas. Para garantir que os coordenadores respondessem o formulário, a primeira pergunta foi seu nome completo, em seguida, qual a categoria de servidor. Após isso, o Campus e a formação de graduação e pós-graduação. Por conseguinte, 2 (duas) perguntas elencando educação empreendedora e a relação com a missão do Instituto Federal de Pernambuco. As últimas 4 (quatro) perguntas levantam temas, como: Experiência empreendedora, estimulo ao empreendedorismo, desafios e a percepção entre caminho acadêmico e abertura de negócios. 
A população de estudo foi, os coordenadores de Extensão de cada Campi do IFPE, sendo enviado para os e-mails de cada departamento de extensão o formulário a cima descrito, no período entre Julho e Agosto de 2021. Totalizando 16 (dezesseis), buscando respostas, a fins de esclarecer a perspectiva dos coordenadores acerca do tema investigado nesse trabalho. Foram obtidas 14 respostas do questionário no total.

Para a seleção da amostra da população do estudo foram utilizados os seguintes critérios de inclusão:

- Ser Coordenador Diretor de Extensão de um dos 16 (Dezesseis) Campi do IFPE;

- Aceitar, de forma voluntária, responder ao questionário enviado por e-mail.

Referente à validação dos questionários recebidos, alguns critérios de exclusão foram aplicados, sendo eles:

- Respondentes que não se enquadrarem nos critérios de inclusão propostos pela pesquisa;

- Participantes que não são Coordenadores de Extensão de um dos Campi do IFPE;

- Coordenadores que respondessem o questionário de forma duplicada, sendo considerado apenas a primeira resposta apresentada.

Por meio de funcionalidade própria do Google Forms, foi feita a coleta dos dados, permitindo o alinhamento das respostas e a formulação dos gráficos. Os pesquisadores realizaram uma análise descritiva dos mesmos, bem como uma discussão do que foi encontrado na Literatura acerca do tema, que será apresentada na próxima seção deste relatório.

\section{RESULTADOS E DISCUSSÃO}

É importante ressaltar que, como resultados dos formulários e analise de literatura servirá, posteriormente, como um instrumento de gestão do conhecimento institucional e processos de tomadas de decisões na criação e/ou fortalecimento de uma cultura organizacional empreendedora. Esses dados, serão alinhados de forma a demonstrar o conceito e a forma da organização IFPE relacionado ao empreendedorismo.

É imprescindível ressaltar que, em contato preliminar com a PROEXT nos foi orientado que, primeiramente, deveríamos solicitar à PROPESQ para que esta verificasse a possibilidade de atendimento ao pleito junto à PROEXT. Então, o instrumento utilizado para solicitar a PROPESQ foi o e-mail, buscamos as informações necessárias como: o Resumo Expandido ou o projeto de pesquisa, para poder viabilizar o plano de trabalho do atual trabalho aprovado, com o plano de atividades: Identificação das atividades extensionistas acerca do tema empreendedorismo em um curso técnico do 


\section{TEMA EMPREENDEDORISMO NO IFPE}

IFPE. Contudo, a resposta foi negativa, então foram necessários uma adequação e novo plano de trabalho: Perspectiva dos Coordenadores de Extensão acerca do tema empreendedorismo no IFPE.

importante ressaltar que essa primeira pergunta, foi utilizada para compreender a categoria que o sujeito de pesquisa se enquadra, entre: docente, técnico administrativo e ambos. Graficamente é explicito que $64,3 \%$ dos servidores são docentes, $35,7 \%$ são técnicos administrativos e não foi obtido resultado na alternativa ambos, como exposto na figura 1.

Figura 1: Categoria dos servidores

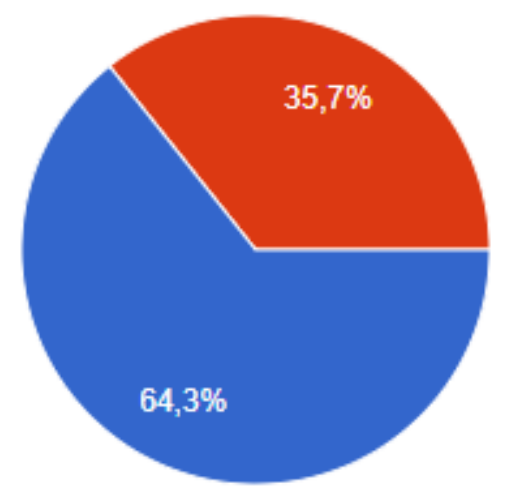

Docente

Técnico Administrativo

Ambos

Fonte: Autoria própria (2021)

Esse tipo questionamento, nos fornece informações valiosas, devido a visão que os docentes ou técnicos administrativos expõem sobre a temática, empreendedorismo, formação empreendedora, protagonismo estudantil e startups.

A Segunda pergunta, demonstra as respostas obtidas através das alternativas de qual Campus o servidor está inserido. Foram alcançadas 14 (quatorze respostas), dentre elas os Campi: Abreu e Lima, Afogados da Ingazeira, Barreiros, Belo Jardim, Cabo de Santo Agostinho, Caruaru, EaD, Garanhuns, Igarassu, Jaboatão dos Guararapes, Palmares, Paulista e Pesqueira, Recife.

A quarta pergunta, foi proposta com o intuito de conhecermos a formação (graduação e pósgraduação) dos sujeitos de pesquisa. Pode-se analisar com as respostas, que dos 14 (quatorze) participantes da pesquisa, 2 (dois) possuem pós-graduação, 8 (oito) mestrado e 4 (quatro) possuem doutorado. Esse tipo de dado, fornece importante conhecimento para provar os diversos tipos de formação e a perspectiva dentro do cenário de conjuntura, podendo então, ser feita uma alusão com pensadores contemporâneos.

Outro ponto pesquisado diz a respeito à Educação Empreendedora tem sido importante para o desenvolvimento de uma nação, sendo reconhecida não apenas no Brasil, mas globalmente e, deste modo, a educação empreendedora pode aumentar e melhorar a qualidade da preparação e o número de jovens inovadores, proativos, e com iniciativa, tanto para trabalharem em uma organização ou de forma autônoma, quanto para tocarem seu próprio projeto. Em ambas as condições, o resultado é um impacto socioeconômico relevante (GUERRA; GRAZZIOTIN, 2010; LIMA Dr.al, 2014a). 
Figura 2: O conceito de "Educação Empreendedora"

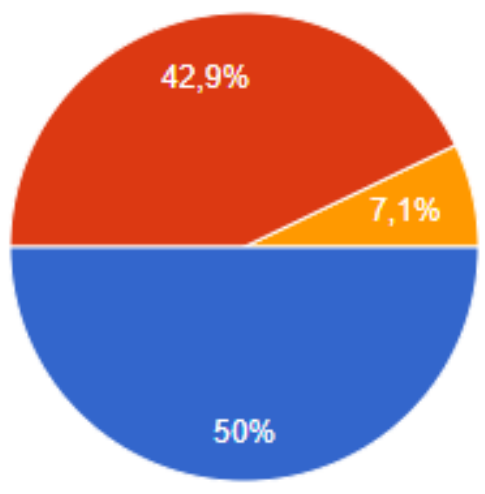

Sim, conheço bem esse tema.

Sim, mas não faz parte de minha área de atuação

Desconheço do que se trata

Fonte: Autoria própria (2021)

Como apresentado na figura 2, a quinta pergunta foi respeitante ao conhecimento dos sujeitos sobre o conceito de educação empreendedora. Analisando a porcentagem e o gráfico obtido através das respostas, $50 \%$ conhecem bem o tema, $42,9 \%$ conhecem o tema, porém não atuam na área e 7,1\% desconhecem o tema. Isso demonstra, que é um tema que aqueles que responderam, conhecem o tema, porém uma porcentagem alta não atua ou não se relaciona no dia a dia com o conceito de educação empreendedora e uma porcentagem baixa, desconhece o assunto.

Respostas as indagações e aumento de entendimento relacionado a esse processo admitiriam a formatação de dinâmicas ou atividades que transportem à educação de pessoas empreendedores. Oliveira e Barbosa (2014) fortalecem a carência de pesquisas e entendimento das vantagens, limitações e decorrências das diversas formas de criar e realizar atividades empreendedoras na educação superior.

De forma a relacionar o tema empreendedorismo, com o IFPE - Instituto Federal de Pernambuco, foi proposto no questionário alternativas, com o foco de perceber a visão dos coordenadores com o tema empreendedorismo e a relação com a missão do Instituto Federal de Pernambuco: "Sim, totalmente. Sim, mas de forma colateral, complementar à formação do estudante. Sim, se o curso for na área de gestão e negócios. Não, a instituição é pública e tem finalidade social, dessa forma não guarda relação com empreendedorismo. Não sei responder com segurança". Como exposto na figura 3 :

Figura 3: Relação do empreendedorismo com a missão do IFPE 


\section{TEMA EMPREENDEDORISMO NO IFPE}

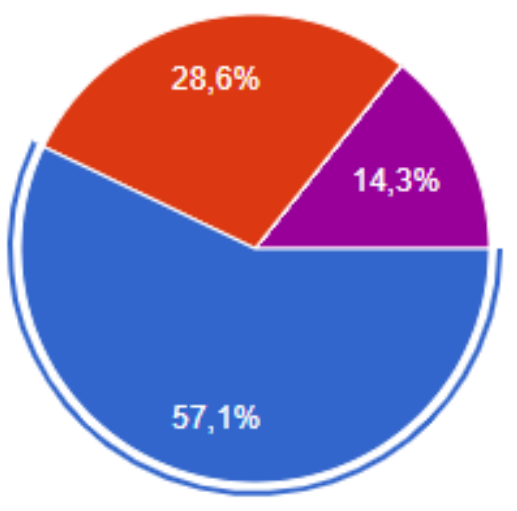

Sim, totalmente.

Sim, mas de forma colateral, complementar à formação do estudante

Sim, se o curso for na área de gestão e negócios

Não, a instituição é pública e tem finalidade social, dessa forma não guarda relação com empreendedorismo

Não sei responder com segurança.

Fonte: Autoria própria (2021)

Cabe a analise a partir da figura 3 , que $57,1 \%$ dos questionados, responderam que sim, o empreendedorismo tem total relação com a missão do IFPE. $28,6 \%$, responderam sim, mas de forma colateral à complementar a formação do estudante e 14,3\% não sabem responder com segurança o questionamento. Isso prova uma divisão entre os sujeitos de pesquisa, em sua maioria a relação com missão existe, diretamente, ou seja, é algo intrínseco ao proposto pela instituição IFPE, porém uma visão paralela apresenta uma colateralidade, em outras palavras, seria uma forma de complementar a formação dos estudantes. Vale destacar não existiu resposta contra essa temática, e sim a minoria não soube responder com segurança.

A sétima pergunta foi proposto aos questionados, se possuíam algum tipo de experiência com Empresa Júnior, Incubadoras, Aceleradoras ou "Startups". Esse tipo de informação, apresenta a prática e aprendizado dos Coordenadores de Extensão, com as diversas formas de empreendedorismo, hoje, possíveis de implementar na prática em Institutos, Universidades, Faculdades, entre outros.

Os resultados foram obtidos do seguinte aspecto, 10 dos entrevistados, não possuem esse tipo de experiência, porém 1 dos mesmos, salienta que o setor de extensão do seu Campus vem buscando novos meios de desenvolvimento nessa área, observando os exemplos da Empresa Júnior do IFPE Cabo de Santo Agostinho e a incubadora do IFPE Olinda. 1 sujeito de pesquisa, acompanha enquanto gestor. Por extensão, cabe denotar que apenas 3 dos pesquisados possuem experiência em alguma dessas áreas, dentre as respostas, afirmaram orientação em plano de negócios sobre o tema patentes, participação em "Startup" na área de projetos e construção e por fim, auxiliando na formação de projetos e a fomentar a Empresa Júnior do IFPE Cabo de Santo Agostinho.

Pode-se discorrer, sobre a possibilidade, apoio e necessidade de uma Instituição em possuir Incubadoras de Empresas, Empresas Júnior, Startups, com o próprio documento do IFPE, o anexo de 2021, que expressa pelo BRASIL. Ministério da Educação. Resolução de $\mathrm{N}^{\circ} 79$, de 1 de Abril de 2021. Artigo IX - "Incubadora de Empresas: organização ou estrutura que objetiva estimular ou prestar apoio logístico, gerencial e tecnológico ao empreendedorismo inovador, com o objetivo de facilitar a criação e o desenvolvimento de empresas que tenham como diferencial a realização de atividades voltadas à inovação". 
A oitava pergunta, trouxe a discussão, a existência no Campus de cada sujeito de pesquisa em ações, programas ou projetos com o objetivo de estimular o empreendedorismo. Esse modelo de pergunta, ajuda a compreensão do empreendedorismo nos Campi do Instituto Federal de Pernambuco, podendo ser feito uma analogia com Dolabela e Filion (2013) que adicionaram que o âmbito de aprendizagem tem o papel de ampliar e desenvolver a confiança e o orgulho do estudante. É preciso ensinar o aluno em uma forma de aprendizagem que exista uma maneira coerente entre ele próprio e a sua perspectiva presente. Os autores afirmam que uma educação empreendedora elenca o contexto de raciocínio, emocional e social do estudante. O desenvolvimento dos estudantes na formação da identidade deve ser gradual com o objetivo de reduzir os conflitos existentes entre os indivíduos e o contexto em que vive. Dessa maneira, os estudantes elevam a autoconfiança para o empreendedorismo.

Pode-se apresentar que, dentre as 14 respostas, 10 afirmaram que sim, nos Campi existem ações, projetos ou programas com o objetivo de estimular o empreendedorismo:

- "Temos O "Festival de Empreendedorismo e Ideias Criativas", realizado anualmente onde os alunos das disciplinas empreendedorismo e marketing realizam pitches com ideias empreendedoras. Atualmente temos dois projetos do Edital IF Mais Empreendedor, são eles: "Driblando a crise com estratégias de marketing digital e gestão financeira" e "Reaprender a empreender para sobreviver! - Um mix de empreendedorismo, inovação e marketing 4. em meio a crise do Covid-19!";

- "Sim. Realizamos ações em parceria com Sebrae, na promoção de palestras e oficinas";

- "Está iniciando no curso de Engenharia de Software, com Os Professores ligados a este curso";

- "Sim, na área de gastronomia, e a própria empresa Júnior”;

- "Sim, através das disciplinas ofertadas nos cursos de IPI, fazendo nas disciplinas de projeto algo semelhante que acontece nas apresentações tipo PIT, trazendo empresas para que eles façam sugestões nos projetos apresentados.";

- "Sim, pelo Pelo programa despertando vocações.";

- "Startup way";

- "Sim. Projeto Marketing Digital para Mulheres Empreendedoras"

Apenas 4 das 14 respostas, afirmaram que no Campus, não existe esse tipo de estimulo ao empreendedorismo. Com esses dados, é possível comentar que a grande maioria dos Campi apresentam incentivo ao empreendedorismo. A respostas foram:

- "Não existem projetos extensionistas ou de Pesquisa sobre a área vigentes. Contudo, existe a pretensão de abrir empresa Júnior quando o curso superior em gestão for 


\section{TEMA EMPREENDEDORISMO NO IFPE}

aberto. Além disso, todos os cursos possuem disciplinas de empreendedorismo com entrega de um plano no final da disciplina";

- "Não que eu me recorde";

- "Atualmente não";

- "NÃO".

A penúltima pergunta, questiona os principais desafios enfrentados como gestor de extensão, para o estimulo e formação de projetos que possam gerar empresas nas áreas de atuação da sua Instituição, as respostas são:

- "Existem apenas dois professores com conhecimento na área de empreendedorismo, ambos sobrecarregados com funções administrativas. Essa sobrecarga administrativa é percebida também pelos professores que não são da área, mas têm interesse de contribuir.";

- "No que diz respeito ao âmbito pessoal, uma formação adequada me ajudaria em uma tratativa mais específica, dada a importância do assunto, bem como uma equipe de servidores comprometida com a proposta do empreendedorismo, uma vez que não conseguimos atuar sozinhos na demanda objeto do presente estudo. Vale salientar que a carga de trabalho só aumenta e o número de servidores permanece o mesmo ou diminui significativamente. ";

- "Falta de engajamento dos pesquisadores.";

- "Por ser ainda uma política recente, dentro do IFPE, ainda há um nível auto de desconhecimento; Também é um prática recente na região, o que também dificulta a existência de clientes. ";

- "Formação do corpo de servidores, tanto docente quanto técnico-administrativa. A promoção de cursos e a publicação de editais institucionais poderiam incentivar mais o engajamento e até mesmo a busca por esses saberes. ";

- "A gestão tenta impulsionar todas as iniciativas de projetos do Campus. O empreendedorismo é forte no Campus, por haver cursos na área de Gestão e Negócios, mas o fortalecimento está ocorrendo gradualmente, como é possível identificar na resposta anterior. ";

- "Necessidade de formação dos docentes e técnicos administrativos para o fomento de iniciativas empreendedoras. ";

- "Conseguir despertar nos docentes o interesse pelo tema, pois são essenciais no processo. ";

- "No momento a pandemia e a crise econômica, onde tem sido cada vez mais difícil inovar com competitividade. ";

- "Fortalecimento das empresas Incubadoras e Empresas Júnior dentro dos Campi. "; 
- “1) FALTA DE ESPAÇO/AMBIENTE É O PRIMEIRO PROBLEMA; 2) INEXISTÊNCIA DA CURRICULARIZAÇÃO DO EMPREENDEDORISMO NA GRADE DE DISCIPLINAS; 3) POUCAS BOLSAS ESTUDANTIS PARA INCENTIVO NA PARTICIPAÇÃO E DESENVOLVIMENTO; 4) FALTA DE DEFINIÇÃO, PELO CAMPUS DE UMA OU DUAS DIRETRIZES DE ATUAÇÃO DESTAS EMPRESAS ";

- "Incentivar o ecossistema empreendedor inovador";

As ultimas 2 respostas, não souberam responder à pergunta, pela justificativa de pouco tempo no cargo e por não trabalhar nessa perspectiva.

Percebe-se que a maioria das respostas se assemelham no quesito organização, engajamento e estrutura. Guerra e Grazzotin (2010) acentuam que o empreendedorismo não deve ser debatido unicamente em disciplinas isoladas ou se prender a sala de aula. As autoras aprovam que o empreendedorismo precisa ser absorvido com veemência, de diversas formas. Trazendo para o contexto, o fortalecimento de uma cultura empreendedora é benéfico para todos os participantes dessa conjuntura.

A décima e última pergunta, foi mais enfática quanto a valorização de estudantes que prosseguem em estudos como mestrado/ doutorado ou para os que abrem negócios. Dessa forma, é possível entender a perspectiva sobre a formação e graus acadêmicos e aqueles que resolvem empreender, abrindo algum tipo de negócio. Como resposta:

- "No geral, a instituição oferece mais incentivos para continuar os estudos. Não é comum incubadoras nos campi, por exemplo. Porém, prosseguir os estudos não é oposição à abrir um negócio. Você pode aprofundar os conhecimentos na a área profissional pelos estudos. ";

- "Essa pergunta é complexa de ser respondida, pois a valorização dependerá de algumas variáveis, como o contexto político, econômico, social etc. Assim sendo, não sei responder esta pergunta com a profundidade necessária. ";

- "Para os que fazem mestrado e doutorado.";

- "Que prossegue os estudos";

- "Na realidade, penso que são duas possibilidades que se abrem para o estudante. Logo, nenhuma seria superior ou melhor que a outra. A escolha, na verdade, estaria mais relacionada com o projeto de vida que o discente almeja para a vida. Mas, penso que instrumentalizar o estudante para que ele tenha essa liberdade de escolha é fundamental. ";

- "É uma resposta difícil de responder. Creio que haja oportunidades nos dois segmentos. Nosso princípio, antes de tudo, é preparar o cidadão para o mundo do trabalho (no sentido amplo do termo). "; 


\section{TEMA EMPREENDEDORISMO NO IFPE}

- "Para o mundo do trabalho vejo uma valorização do estudante que prossegue os estudos com mestrado e doutorado. Entretanto, para os que abrem um negócio, vejo como uma grande estratégia de crescimento econômico pessoal e ruptura das barreiras impostas pelo próprio mundo do trabalho para inserção de novos profissionais, tendo em vista as dificuldades relacionadas ao contexto econômico nacional. ";

- "Essa resposta é muito relativa e tem que se observar algumas variáveis. Caso o aluno encontre um negócio que seja compensador e satisfaça sua vontade, poderá ingressar diretamente, porém se o negócio não tem raízes ou base solida e Ele deixa de fazer mestrado / doutorado para entrar no negócio e não tiver sucesso, se frustará. ";

- "Difere caso a caso. ";

- "Acredito que seja para Mestrado e doutorado"

- "NOS CURSOS TÉCNICOS É MAIS VALORIZADO OS QUE ABREM NEGÓCIOS, NO CURSO SUPERIOR É MAIS VALORIZADO OS QUE SEGUEM CARREIRA ACADÊMICA ”

- "Mestrado/ Doutorado";

- "Como não sou da área, não tenho certeza, mas acredito que o mercado valoriza mais quem abre um negócio e empreende."

- “DEPENDE, CADA CASO É UM CASO, PORÉM NOSSA MISSÃO NO IFPE TEM COMO OBJETIVO FORMAR PARA O MUNDO DO TRABALHO ”

Percebe-se que as respostas foram divididas, porém vale comentar que, enfatizaram que a conjuntura política e social tem relação direta com o momento de abrir um negócio, trazendo à tona discussão de uma maior valorização para os graduados, um mestrado/ doutorado possibilitando uma carreira acadêmica.

\section{CONCLUSÕES}

É compreensível então, que o tema empreendedorismo, educação empreendedora e inovação, são temas e conteúdos atuais, e a eles vêm sendo atribuídos bastante atenção e trabalho, pelos autores e instituições de ensino brasileiras, visando sempre a busca por inovação e perspectivas, que compreendam o não apenas o cenário atual, mais sim o futuro.

Faz-se necessário destacar, então, que existem diversos aspectos que particularizam um empreendedor, tais como: inovação, planejamento, constância, entre outros. Dessa forma, é possível verificar por meio de formulários e contato com os coordenadores de extensão do IFPE, a visão dos mesmos, relacionada ao tema Empreendedorismo, com isso, criando um estudo sobre a asserção. É importante observar que o âmbito pessoal e profissional dos 
entrevistados foram expostos e interligados com a literatura estudada.

Pode-se ressaltar que após a pesquisa foi possível obter resultados especificos, relatados pelos Coordenadores de extensão, como o avanço, ao passar dos anos, de ações empreendedoras nos 16 Campi do IFPE, 10 destes apresentam, projetos, programas, Empresas Juniores, Encubadoras, que possuem o objetivo de estimular o empreendedorismo. Outro ponto necessário que foi posicionado pelos questionados, foi a realçao do empreendedorismo com a missão do IFPE, 85,7\% acreditam que está relacionado diretamente ou de forma colateral.

Além dos principais avanços foi possivel identificar as maiores dificuldades de estimulo e formação de projetos capazes de gerar ações empreendedoras, pela visão dos sujeitos de pesquisa, a falta de professores na área de empreendedorismo afeta diretamente nesse tipo de projeto, para mais a falta de uma equipe de servidores, que estajam alinhados e motivados para o crecimento e implementação desse tipo de ação. Outros pontos fundamentais apontados, foram a falta de interesse dos docentes, acrescentado a isso, poucas bolsas para os estudantes.

É coerente sustentar que o ato de empreender não é apenas uma forma de acervo de estudos, contudo a formação e a construção de uma cultura, princípios, atitudes, autoconhecimento, capacidade de inovação, arriscar e construir com o intuito de tornar circunstancias para benefício prático, de mesmo errando, aprender e continuar diante adversidades.

\section{REFERÊNCIAS}

BRASIL. Ministério da Educação. Resolução de $\mathrm{N}^{\circ}$ 79, de 1 de Abril de 2021.

BRASIL. Lei de Diretrizes e Bases da Educação Nacional. Lei número 9394, 20 de dezembro de 1996.

CUNHA, R. M.; SOARES, E. L.; FONTANILLAS, C. N. As vantagens de aprendizado do empreendedorismo: um estudo desde o ensino de base até o superior. Revista Pensamento contemporâneo em Administração, Rio de Janeiro, v. 3, n. 3, p. 62-73, set/dez. 2009

Dolabela, F. \& Filion, L. J. (2013). Fazendo revolução no Brasil: a introdução da pedagogia empreendedora nos estágios iniciais da educação. Revista de Empreendedorismo e Gestão de Pequenas Empresas, 3(2), 134-181.

GUERRA, M, J; GRAZZIONTIN, Z.J. Educação empreendedora nas universidades brasileiras.

LOPES, R, M. A. Educação Empreendedora: conceitos, modelos e práticas. Rio de Janeiro: Elsevier, 2010. LOPES, R, M. A. Qual é o perfil do empreendedor? Revista da ESPM, São Paulo, v. 19, n. 2, p. 64-71, mar/abr. 2013 
OLIVEIRA, J.; BARBOSA, M. L. Processo de seleção de pré-incubação: sob a batuta da subjetividade. In: GIMENEZ, F. A. P. et. al. (org.) Educação para o empreendedorismo. Curitiba: Agência de Inovação da UFPR, 2014. Título: Empreendedorismo e educação empreendedora: confrontação entre a teoria e prática (V. 8, n. 15, jan/jun. de 2006) Autor: Tatiana V. A. Ribeiro RIBEIRO, Ricardo, OLIVEIRA, Edson, ARAUJO, Elvira. A contribuição das instituições de ensino superior para a educação empreendedora. Abril de 2014.

TSCHÁ, E. R.; CRUZ NETO, G.G. Empreendendo colaborativamente ideias, sonhos, vidas, e carreiras: o caso das células empreendedoras. In: GIMENEZ, F. A. P. et. al. (org.) Educação para o empreendedorismo. Curitiba: Agência de Inovação da UFPR, 2014 